\title{
The Development of Media Isan Folk Music Education for Student
}

\author{
${ }^{1}$ Yothin Phonkhet, ${ }^{2}$ Tanaporn Phonkhet \\ ${ }^{1,2}$ Roi-Et College of Dramatic Arts., Thailand
}

\section{Abstract:}

This research aims to: 1) develop media Isan folk music education for student 2) study the learning achievement before and after class of students studying using media Isan folk music education.

The instruments used in the research were 1) media Isan folk music education 2) Learning achievement test in the form of 20 questions with 4 choice answers. Statistics used in data analysis are percentage, mean, deviation Standard and t - test (Independent Samples). The study found that:

1) The developed media Isan folk music education was efficient as $89.28 / 86.47$

2) Students studying with media folk music education had higher learning achievement after studying with media Isan folk music education with statistical significance at the level of .05

Key word: Media, Isan Folk Music.

\section{1- Introduction}

In designing computer lessons, the instructor must have the instructor and have guidelines for designing according to the learning theory. Which the theory of learning has many theories each theory has a different concept, the designed lesson should be able to stimulate student's interest in learning and appropriate contents in order to initiate critical thinking skill. (Pisuth Areerat, 2012: 41)

The researcher has developed educational media for playing Isan folk music. By demonstrating each tool step-by-step from the basic skills to advanced skills, students in the fields of art, music and folk performances are able to access the knowledge of Isan folk music at any time without limiting to the location and time. It helps to solve the problem of teaching in a classroom that is tied with specific class time and instructor. Based on this significance, researcher, therefore, developed the teaching media to teach Isan folk music and performance for students in the fields of art, music and folk performances at Bunditpatanasilpa Institute 
and those who are interested in learning Isan music. By introducing information technology as a tool for organizing activities of Isan folk music, student's learning skill is developed effectively along with the know-how of the 21 st century.

\section{Research objectives}

1. To develop educational media for learning to play Isan folk music for students

2. To compare learning achievement before and after studying with the educational media

\section{The significance of research}

1. Create educational materials, for learning to play Isan folk music.

2. To be a guideline to enhance the performance of Isan folk music and so that students can learn the media of Isan folk music without being limited in time and place to develop into lifelong learning

\section{Research hypothesis}

Learners who study with educational media, for learning to play Isan folk music will have higher learning achievement after studying with an efficiency criteria or at least 70/70

\section{Research scope}

For this study to meet the objectives set the researcher has defined the scope of research as follows.

Step 1: Study documents, principles, concepts, theories and related research. About educational media enhancing the learning of music to apply the principles to create the educational media.

Step 2: Study basic information on the need to use educational materials by using questionnaires to explore basic information as follows.

2.1 Study the need for educational media using a set the framework of 4 questions: 1) Activities 2) Objectives 3) Content 4) Educational media

\subsubsection{Population and sample group}

2.1.1.1 The population used in this study is students of Bunditpatanasilpa Institute, a total of 20 people

2.1.1.2 Sample groups of 20 people were selected using Cluster Random Sampling by selecting 10 people from each representative institution.

The proportion of sample groups was determined by using a proportional stratified random sampling 


\section{International Academic Conference on Teaching, Learning and Education}

MILAN, ITALY

method according to the sample size from the opening table of Krejcie and Morgan (Krejcie and Morgan) (1970:607-610)

2.2 Study variables

2.2.1 Independent Variables: learning by using educational media on Isan folk music for students at Bunditpatanasilpa Institute.

2.2.2 Dependent Variables are the learning achievement from the study of the media of Isan folk music and opinions of students at Bunditpatanasilpa Institute

2.2.3 The instrument used in the research is the questionnaire

\section{2- RESULT OF RESERACH}

1. To develop educational media for learning to play Isan folk music for students. The need for using media to study Isan folk music

1.1 the needs of the instructor and students who study of the Isan folk music can conclude that the instructors and students are in need of media to play Isan folk music. When considering the instructor sort the average from descending to the content designation. Objective setting resources in the cooperative learning process and how to practice playing as for the need for media of the students sort the average value from descending to the cooperative learning process. Training methods content designation objective and the need for playing Isan folk music.

1.2 Results of the study of characteristics and elements of media in conclusion there are 6 important elements that are consistent: analyze needs determining the purpose, media content creation

, selection of techniques and design of media the implementation of media development and evaluation of media development.

1.3 Results of the study of elements of Isan folk media in conclusion, the elements of Isan folk media have studied there are 6 important elements that are consistent: analyze needs determining the purpose of multimedia media multimedia content creation selection of techniques and design of media The implementation of media development and evaluation of media development. Analysis and synthesis of elements related to media in conclusion, the media elements have two important elements: in terms of presentation and content

Analysis and synthesis of elements related to media consistent, defined as a component of media It can be concluded that there are 5 important elements that are consistent: the alphabet, animation, sound, content and presentation style. Analysis and synthesis of the media development process can be concluded. That the process of making media that each educator has studied the 3 important consistency is preparation, operation and evaluation.

To develop educational media for learning to play Isan folk music for students with the following results: 


\section{International Academic Conference on Teaching, Learning and Education}

MILAN, ITALY

1) The student's ability to play Isan folk music and knowledge and attitude towards using technology after the training was significantly higher than before training at the level of .05 .

2) The students have Isan folk music skills and have practical skills at the operational level.

3) The students have a cooperative learning feature. Sort by percentage, total, each side, from descending to the aspect of group process characteristics aspects of the person's responsibility and aspects of mutual support as for the use of skills between individuals, the highest mean is counseling.

4) The students are satisfied with the media for learning the Isan folk music at a high level.

Performance analysis step, design stage, developmental capability procedures and assessment steps the research found that student with training, knowledge and qualifications with different scores before training and after training, with statistical significance at .05 level,

2. To compare learning achievement before and after studying with the educational media

The comparison showed that their mean posttest score was significantly higher than the pretest at the 0.05 level of significance.

The students are satisfied with the media of Isan folk music at a high level. Because multimedia can meet the needs communicate with teachers and learners together more according to the communication channel provided students are excited, fun and eager to participate in the training. A lot of information is provided to learners. Build skills in creating knowledge in a systematic way support communication and cooperative learning which makes the atmosphere.

Figure 1: achievement before and after studying

Table 1

\begin{tabular}{c|l|l|ll|l|}
\hline \hline result & $\bar{X}$ & S.D. & T & $\mathrm{p}$ \\
\hline Pretest & 24.80 & 4.26 & 6.63 & $.002 * *$ \\
\hline Posttest & 27.47 & 4.02 & & \\
\hline \hline
\end{tabular}




\section{International Academic Conference on Teaching, Learning and Education}

MILAN, ITALY

\section{CONCLUSION}

Instructors and students have a need media in learning the Isan folk music. All aspects are at a high level. Assessment of traditional performance of Folk Music for student's current competencies in Isan folk music playing are at a moderate level. The media of Isan folk music for students was developed by the researcher according to the principles of multimedia, Isan folk music and current performance studies, and the competencies needed for Isan folk music play. By the developed multimedia, the qualified person sees that it is appropriate at the highest level and a cooperative training web site built according to the multimedia model with the effectiveness index of 0.5647 , with the knowledge gained by 0.5647 or $56.47 \%$.

The learners have the ability to play Isan folk music using media, after training of music was higher than before training of music with a statistical significance offering opinions through the web is a process like training in the room, but connects the trainees with the training manager by the internet The training can change the information to be up to date quickly and the interaction from such characteristics has resulted in the students having knowledge, competency, and a favorable attitude towards the use of media of Isan folk music technology.

Has been systematically developed according to the research process Enabling students to learn by themselves, media about Isan folk music, therefore is a suitable medium can be used as the main media for organizing teaching and learning activities as well or can be used as supplementary media for students to review their knowledge in addition, the media can also be used as a medium for people interested in music.

\section{SUGGESTION}

1. Should study the development of musical instrument in various forms during the study on the web and blended learning in order to create better interaction between learners and instructors.

2. Should study the results of the experiment using educational media, playing Isan folk music by comparing the learning characteristics of the experimental group and the control group studied in the classroom.

3. Should study and compare the level of cooperation and interaction in the use of multimedia, Isan folk music to enhance the capacity of technology due to 


\section{International Academic Conference on}

MILAN, ITALY

\section{Teaching, Learning and Education}

different levels of cooperation and interaction may affect student achievement and performance.

4. should study the effectiveness of educational media, playing the Isan folk music based on the calculation of E1 / E2 values, in addition to calculated from the score of the performance of Isan folk music, knowledge should be scored from the assessment of practical skills or attitude towards using educational media used to calculate E1 / E2 as well.

\section{REFERENCES}

[1] Byar, L.L., \& Rue, L.W. Human Resource Management. (Fifth Edition) New York: Mc Graw-Hill, 1997.

[2] Relan, A.and B.B. Gillani. "Web-Based Instruction and the Traditional Classroom: Similarities and Differences." In Web-Based Instruction, 98-101. Englewood Cliffs, NJ: Prentice-Hall,1997. 